\title{
Patrón de metilación génico en el cáncer de mama
}

\author{
Juan Carlos Roa S, Leonardo Anabalón R, Oscar Tapia E, \\ Javier Martínez S, Juan Carlos Araya O, Miguel Villaseca H, \\ Pablo Guzmán G, Iván Roa E.
}

\author{
Promoter methylation profile in \\ breast cancer
}

Background: Genomic DNA methylation, mutations and allelic deletions explain the inactivation of genes involved in cell proliferation and cell cycle control mechanisms. Aim: To analyze the methylation pattern of important genes related to different carcinogenic mechanisms in patients with breast cancer and the relationship with its biological behavior. Material and methods: Seventy fresh-frozen breast cancer samples were selected. The methylation specific PCR (MSP) test was used to analyze promoter methylation status for genes CDKN2A (p16), hMLH1, APC, CDH1 (Cadherin E) and FHIT. Results: We found methylation in at least one of the genes studied in $88 \%$ of cases and in 3 or more genes in $40.5 \%$ of cases. The frequencies of promoter hypermethylation of CDKN2A, hMLH1, APC, CDH1 and FHIT were $41.4 \%, 11.4 \%, 52.9 \%, 70 \%$ y $42.9 \%$, respectively. We found a relationship between CDKN2A methylation and better survival $(\mathrm{p}=0.002)$. CDH1 methylation and poor histological differentiation ( $\mathrm{p}=0.007$ ), hMLH1 methylation and non-Mapuche ethnicity ( $\mathrm{p}=0.03$ ), APC methylation and larger tumor size ( $p<0.05$ ), FHIT methylation and lack of estrogen receptor IHC expression $(p<0.05)$. Conclusions: The high frequency of promoter methylation in patients with breast cancer confirms its role in breast carcinogenesis. The finding of alterations in the methylation pattern of genes studied and its association with prognostic factors is a helpful tool in the search of new criteria for clinical and therapeutic decision making (Rev Méd Chile 2004; 132: 1069-77).

(Key Words: Breast neoplasms; CDKN2A protein; DNA probes; Genes, P16)

Recibido el 4 de marzo, 2004. Aceptado en versión corregida el 1 de julio, 2004.

Departamento de Anatomía Patológica, Universidad de La Frontera, Temuco, Chile.

$\mathrm{E}^{\mathrm{n}}$ Chile, el cáncer de mama es la tercera causa de muerte por cáncer en las mujeres y la segunda causa de muerte por cáncer entre las mujeres mayores de 50 años, con una tasa de mortalidad general de 13 por cada 100.000 mujeres $^{1}$. Se estima que el envejecimiento paulatino de

$\overline{\text { Correspondencia a: Dr. Juan Carlos Roa. Departamento de }}$ Anatomía Patológica, Facultad de Medicina, Universidad de la Frontera. Manuel Montt 112. Código Postal 478-1176, Temuco, Chile. E mail: jcroa@ufro.cl la población chilena, provocará un aumento significativo en las cifras absolutas de cáncer en el grupo de población de mayor riesgo ${ }^{1}$. La frecuencia de esta neoplasia es tal en países industrializados, que la probabilidad que una mujer, que vive hasta los 75 años de edad desarrolle un cáncer de mama durante su vida es de aproximadamente $5 \%$.

En cáncer de mama se han identificado numerosos factores involucrados en la carcinogénesis mamaria. La mayoría corresponden a alteraciones 
genéticas como las mutaciones de los genes BRACA1 y BRACA2 en cánceres familiares de mama $^{5-7}$ y activación de oncogenes e inactivación de genes supresores de tumores en cánceres esporádicos ${ }^{8-10}$.

En el último tiempo ha cobrado importancia la participación de las alteraciones epigenéticas en el desarrollo del cáncer. Es decir, una serie de procesos que modifican la función de un gen, pero que no conllevan modificación de la secuencia de ADN. Estas alteraciones epigenéticas son aparentemente muy frecuentes y particularmente importantes en neoplasias en humanos. Porque pueden explicar la participación de agentes ambientales en la tumorogénesis como la dieta y la exposición a carcinógenos, afectando diversas vías carcinogenéticas simultáneamente ${ }^{11-13}$. La metilación del ADN es el cambio epigenético más frecuente e importante hasta ahora estudiado. Ocurre normalmente en vertebrados y está involucrado en la regulación transcripcional de genes en el período de embriogénesis y en la inactivación del cromosoma $\mathrm{X}^{14}$. En las células tumorales existe un estado de hipometilación del ADN genómico pero de hipermetilación en regiones ricas en citocinas y guaninas (islotes $\mathrm{CpG})$, los cuales tienen aproximadamente entre 500 a 2.000 pb de largo y que están ubicadas frecuentemente cercanas o dentro de las áreas promotoras génicas en aproximadamente la mitad de los genes humanos conocidos ${ }^{12,15}$. La hipermetilación de estas áreas produce represión transcripcional debido a un cambio estructural de la cromatina, que la hace inaccesible a los factores de transcripción, pudiendo, de esta manera, inactivar genes supresores de tumores; lo que se pensaba ocurría exclusivamente por deleción alélica o mutación. Este fenómeno se ha observado en varios tipos de tumores donde se expresarían patrones de metilación específicos ${ }^{16,17}$.

Se han utilizado técnicas de Southern ${ }^{18}$ en el estudio de la metilación del ADN genómico. Sin embargo, requiere grandes cantidades de ADN metilado en los alelos estudiados. Técnicas que combinan la acción de enzimas de restricción seguido de amplificación (PCR) requieren de alta pureza celular para eliminar errores de interpretación ${ }^{19}$. En los últimos años ha surgido una prueba que permite el análisis de múltiples áreas metiladas. Esta técnica denominada Methylation Specific PCR (MSP) ${ }^{20}$ ha sido extensamente utilizada gene- rando enormes cantidades de información. La comprobación de que las áreas amplificadas se encuentran metiladas se puede hacer mediante la técnica de Bisufite sequencing con un alto grado de concordancia.

El objetivo de este trabajo es evaluar el perfil de metilación de 5 genes involucrados en distintas vías carcinogenéticas: CDKN2A (p16), APC (Adenomatous Poliposis Coli) y FHIT (Fragile Histidine Triad) correspondientes a genes supresores de tumores relacionados con el control del ciclo celular21. El gen hMLH1 probablemente el más importante dentro de la familia de genes reparadores de ADN genómico (Human Mut.Homologue1)22 y el gen CDH1 (Caderina E), que codifica una proteína de transmembrana que actúa como molécula de adhesión y que participa en la metástasis y en la invasión tumoral ${ }^{23}$.

Genes seleccionados para el estudio. Los genes fueron seleccionados debido a su importancia en la carcinogénesis en humanos y porque se han mostrado frecuentemente metilados en otros tumores ${ }^{24}$.

El gen hMLH1 (ubicado en 3p21-23) es el más importante en una familia de genes relacionados con la reparación del ADN desalineado y representa a un emergente grupo de tumores que se caracteriza por una alta frecuencia de errores de replicación conocida como inestabilidad microsatelital ${ }^{25}$.

La inactivación del gen APC (ubicado en 5q21) es frecuente en cáncer de colon y recto y se observa en el 100\% de los casos asociados a poliposis familiar congénita, en estos individuos esto ocurre en general por mutaciones de detención que truncan al producto proteico génico ${ }^{26,27}$. La metilación de las áreas promotoras se ha propuesto como un mecanismo alternativo de inactivación en grupos de pacientes que no presentan estas mutaciones ${ }^{28}$.

El gen supresor de tumores CDKN2A (ubicado en 9p21) se encuentra relacionado con el control del ciclo celular, su acción en la carcinogénesis ha sido intensamente estudiada, encontrándose inactivado en una serie de tumores especialmente melanoma, páncreas y estómago presentando además correlación con factores morfológicos y pronósticos ${ }^{29-31}$.

En el caso del gen FHIT (ubicado en 3p14.2), corresponde a un gen supresor de tumores que se 
inactiva más frecuentemente mediante $\mathrm{LOH}$ en varios tipos de cáncer incluidos el bronquial y de mama, siendo las mutaciones más bien infrecuentes 32,33 . Sin embargo existen evidencias que la hipermetilación del promotor sería un mecanismo importante en la inactivación de este gen ${ }^{33}$.

La Caderina E (CDH1) (ubicada en 16q22.1) corresponde a un tipo de molécula de adhesión fuertemente relacionada con el desarrollo del cáncer especialmente con aspectos asociados a la invasión y metástasis ${ }^{23,34}$. Varias comunicaciones han mostrado que la actividad reducida de Caderina E se relaciona con peor pronóstico ocupando la metilación un papel protagónico ${ }^{35,36}$.

\section{MATERIAL Y MÉTODOS}

Casos. Se seleccionaron 70 casos de cáncer de mama del banco de tumores congelados del Departamento de Anatomía Patológica de la Universidad de la Frontera. Todas las muestras fueron mantenidas en gel criopreservante (Jung, Alemania) a $-70^{\circ} \mathrm{C}$. Para la obtención del material en estudio se seleccionó un área tumoral mediante corte de congelación y se fragmentó en cámara fría.

Extracción del ADN. Se realizó según procedimiento adaptado del protocolo del Kit de Aislamiento de ADN Genómico Puregene (GENTRA, USA). Brevemente, los fragmentos de tejido se incubaron a $65^{\circ} \mathrm{C}$ en Microtubos tubos de $1,5 \mathrm{ml}$ con solución de lisis celular y proteinasa K (10 $\mathrm{mg} / \mathrm{ml}$ ) hasta observar lisis tisular total. Las proteínas fueron eliminadas por precipitación en acetato de amonio 7,5 M. El ADN fue precipitado con isopropanol, lavado con etanol $70 \%$, resuspendido en solución de hidratación y almacenado a $-20^{\circ} \mathrm{C}$.

Modificación con Bisulfito. El principio de la modificación de ADN con la técnica de bisulfito de sodio se basa en su capacidad de convertir a todos los residuos de citosina (C) no metiladas en uracilos (U) mediante deaminación, pero cuando la citosina está metilada es resistente a la reacción y permanece como citosina ${ }^{20}$. Los iniciadores de PCR utilizados aprovechan estas diferencias para discriminar entre aquellas frecuencias metiladas y no metiladas. Se usó protocolo previamente descrito ${ }^{20}$. Brevemente, $2 \mu \mathrm{g}$ de ADN fueron desnatu- ralizados incubando a $75^{\circ} \mathrm{C}$ por $15 \mathrm{~min}$ en un volumen de $22 \mu \mathrm{l}$ con $\mathrm{NaOH}$ (concentración final $0,27 \mathrm{~N})$. Se agregó hidroquinona y bisulfito de

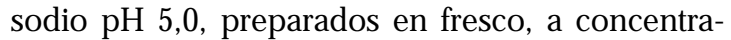
ciones finales de $50 \mu \mathrm{M}$ y 4,2 M respectivamente, seguido de una incubación a 50ํㅡ durante $16 \mathrm{~h}$. El ADN modificado fue purificado y concentrado usando tubos Centricon YM 30 (Millipore). La desulfonación se llevó a cabo agregando $\mathrm{NaOH}$ a una concentración final de 0,3 $\mathrm{N}$ e incubando a 370 $\mathrm{C}$ durante $15 \mathrm{~min}$. Después de neutralizar la solución con acetato de amonio, se precipitó durante toda la noche a $-20^{\circ} \mathrm{C}$ con 3 volúmenes de etanol en presencia de glicógeno. Finalmente, se resuspendió en $80 \mu \mathrm{l}$ de agua deionizada y utilizó en un período inferior a 2 semanas siguientes.

Amplificación del ADN. Las condiciones particulares de PCR y las secuencias de los partidores se encuentran detalladas en la Tabla 1.

Las PCR fueron realizadas con aproximadamente $100 \mathrm{ng}$ de ADN genómico modificado, 0,2 $\mu \mathrm{M}$ de cada iniciador, $200 \mu \mathrm{M}$ de cada uno de los desoxinucleótidos trifosfatos, $1,5 \mathrm{mM}$ de $\mathrm{MgCl}$ y 0,75 U de Taq Polimerasa (Promega) en un volumen final de $25 \mu \mathrm{l}$. Se usó como control negativo $100 \mathrm{ng}$ de ADN genómico sin modificar, a la vez de un blanco de mezcla de reacción sin ADN. Como control positivo de metilación se utilizó ADN genómico comercial (Promega) metilado con SssI (Biolab) y como control positivo de ADN no metilado se usó el mismo ADN sin metilar modificado.

Los partidores usados se detallan en la Tabla 1.

Una vez que se realizaron las reacciones de PCR, los resultados fueron visualizados mediante electroforesis en gel de agarosa al $2 \%$ en buffer TAE y teñidos con bromuro de etidio.

Estadística. La relación entre el estado de metilación génica con variables categóricas, tales como sexo, raza, tipo histológico, se estableció usando la prueba de $\chi^{2}$ o la prueba exacta de Fisher. Para variables numéricas como edad se utilizó la prueba de t-student. Para el cálculo de sobrevida y su asociación con parámetros morfológicos y clínicos y del status de metilación génica se construyeron múltiples curvas de Kaplan Meier y fueron comparadas utilizando la prueba de logrank y el modelo de Cox Hazard. 


\section{RESULTADOS}

Características clínicas. Las características generales del grupo estudiado se observan en la Tabla 2. Esta fue mayoritariamente de sexo femenino y no mapuche $(98,6 \%)$ y $(92,9 \%)$ respectivamente, presentando una edad promedio de 58,6 años (rango 29-88 años). Sólo 4 (5,7\%) pacientes eran menores de 40 años y sin antecedentes familiares de cáncer y $17(24,3 \%)$ se encontraban entre los 40 y 50 años. La sobrevida global hasta 5 años fue de $60 \%$, obteniéndose para el grupo analizado un rango de seguimiento de 6 a 93 meses, con un promedio de 55,4 meses de sobrevida.

La etapificación según TNM concentró la mayoría de los casos en las etapas 2 y 3 (58,7\% y $21,4 \%$ respectivamente). Los estadios 1 y 4 presentaron frecuencias cercanas al 10\% (12,8\% y 7,1\% respectivamente).
El tipo histológico más frecuente fue el ductal con $88,7 \%$ y los menos frecuentes fueron del tipo medular y mucinoso, ambos con 2,8\%. En relación al grado de diferenciación del tumor, encontramos $18,5 \%$ para el grado $1,55,7 \%$ para el 2 y de $25,8 \%$ para el 3.

Estado de metilación génica. La frecuencia de metilación de las áreas promotoras de los genes estudiados para los 70 tumores de mama analizados (Tabla 3), fluctuó entre 11,4\% para hMLH1 y $70 \%$ para CDH1 (Caderina E), los genes CDNK2A (p16), APC y FHIT presentaron frecuencias de metilación similares entre 40\% y 53\% (Tabla 3).

El índice de metilación es un indicador que muestra la proporción de áreas promotoras metiladas respecto de genes estudiados, se calcula dividiendo el número de genes metilados por número de genes estudiados. Los resultados se

Tabla 1. Secuencia de iniciadores y condiciones de PC R ( N M =no metilado; $M=$ metilado)

\begin{tabular}{|c|c|c|c|c|c|}
\hline $\begin{array}{l}\text { Iniciadores } \\
\text { p16 }\end{array}$ & \multicolumn{2}{|c|}{ Secuencia 5'-3' } & \multirow{2}{*}{$\begin{array}{c}\begin{array}{c}\text { Temperatura } \\
\text { Hibridación } \\
\left({ }^{\circ} \mathrm{C}\right)\end{array} \\
60\end{array}$} & \multirow{2}{*}{$\begin{array}{c}\mathrm{n}^{0} \\
\text { ciclos } \\
35\end{array}$} & \multirow{2}{*}{$\begin{array}{r}\begin{array}{r}\text { Tamaño } \\
\text { Producto } \\
(\mathrm{pb})\end{array} \\
151\end{array}$} \\
\hline & $\mathrm{NM}$ & $\begin{array}{l}\text { TTATTAGAGGGTGGGGTGGATTGT } \\
\text { CAACCCCAAACCACAACCATAA }\end{array}$ & & & \\
\hline & $\mathrm{M}$ & $\begin{array}{l}\text { TTATTAGAGGGTGGGGCGGATCGC } \\
\text { GACCCCGAACCGCGACCGTAA }\end{array}$ & 63 & 35 & 150 \\
\hline \multirow[t]{2}{*}{ hMLH1 } & NM & $\begin{array}{l}\text { TTTTGATGTAGATGTTTTATTAGGGTTGT } \\
\text { ACCACCTCATCATAACTACCCACA }\end{array}$ & 60 & 44 & 124 \\
\hline & $\mathrm{M}$ & $\begin{array}{l}\text { TATATCGTTCGTAGTATTCGTGT } \\
\text { TCCGACCCGAATAAACCCAA }\end{array}$ & 60 & 44 & 153 \\
\hline \multirow[t]{2}{*}{ FHIT } & NM & $\begin{array}{l}\text { TTGGGGTGTGGGTTTGGGTTTTTATG } \\
\text { CATAAACAACACCAACCCCACTA }\end{array}$ & 66 & 35 & 74 \\
\hline & $\mathrm{M}$ & $\begin{array}{l}\text { TTGGGGCGCGGGTTTGGGTTTTTACGC } \\
\text { CGTAAACGACGCCGACCCCACTA }\end{array}$ & 66 & 35 & 74 \\
\hline $\mathrm{CDH} 1$ first round & & $\begin{array}{l}\text { GTTTAGTTTTGGGGAGGGGTT } \\
\text { ACTACTACTCCAAAAACCCATAACTAA }\end{array}$ & 50 & 20 & 270 \\
\hline \multirow[t]{2}{*}{ CDH1 second round } & NM & $\begin{array}{l}\text { TGGTTGTAGTTATGTATTTATTTTTAGTGGTGTT } \\
\text { ACACCAAATACAATCAAATCAAACCAAA }\end{array}$ & 62 & 35 & 120 \\
\hline & $\mathrm{M}$ & $\begin{array}{l}\text { TGTAGTTACGTATTTATTTTTAGTGGCGTC } \\
\text { CGAATACGATCGAATCGAACCG }\end{array}$ & 64 & 35 & 112 \\
\hline \multirow[t]{2}{*}{ APC $1 \mathrm{~A}$} & NM & $\begin{array}{l}\text { GTGTTTTATTGTGGAGTGTGGGTT } \\
\text { CCAATCAACAAACTCCCAACAA }\end{array}$ & 55 & 44 & 108 \\
\hline & M & $\begin{array}{l}\text { TATTGCGGAGTGCGGGTC } \\
\text { TCGACGAACTCCCGACGA }\end{array}$ & 55 & 40 & 98 \\
\hline
\end{tabular}


Tabla 2. C aracterísticas generales y morfológicas del grupo estudiado $n=70$

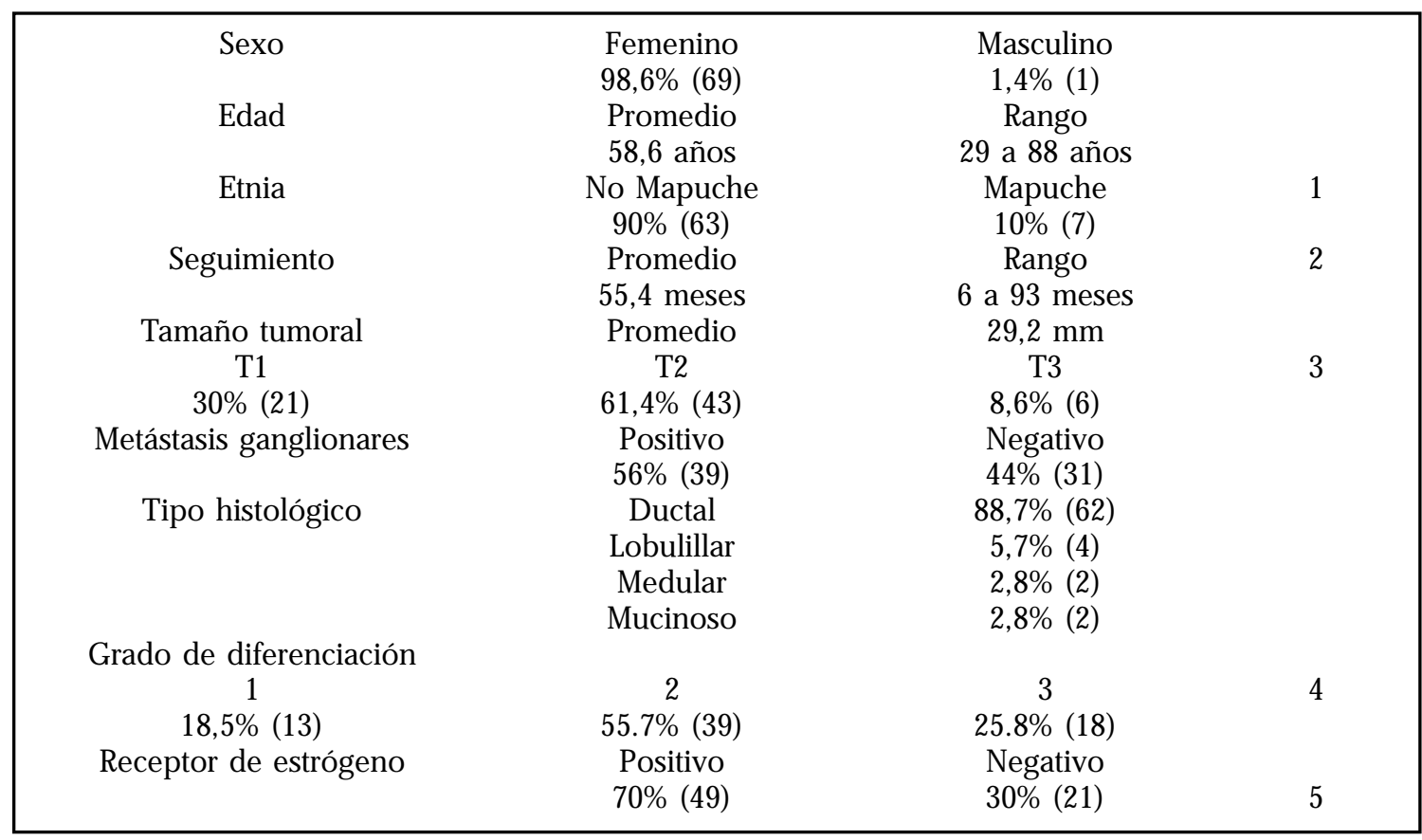

1 hMLH1 Asociado a población no mapuche $(p=0,03)$

2 CDKN2A Asociado a mejor sobrevida $(\mathrm{p}=0,002)$

3 APC Asociado a mayor tamaño tumoral $(p<0,05)$

4 CDH1 Asociado a menor grado de diferenciación $(p=0,007)$

5 FHIT Asociado a ausencia de receptores de estrógeno mediante estudio IHQ $(p<0,05)$

observan en la Tabla 4 distribuyéndose en forma homogénea en cada categoría con la excepción de un solo caso que mostró metilación en todos los genes analizados (Tabla 4).

Cuando analizamos el estado de metilación de cada gen y lo correlacionamos con características anátomo-clínicas se observó diferentes tendencias para los genes en estudio (Tabla 2). Brevemente, encontramos mayor sobrevida cuando CDKN2A estaba metilado $(p=0.002)$, menor diferenciación tumoral cuando CDH1 presentaba metilación $(\mathrm{p}=0,007)$, y una frecuencia menor de metilación en pacientes de raza mapuche para hMLH1 $(p=0,03)$. Por último, los tumores con metilación del gen APC presentaban en promedio un mayor tamaño tumoral y menor diferenciación $(p<0,05)$. Para el gen FHIT se observó una tendencia no significativa a estar metilado cuando no había presencia de receptores de estrógeno y progesterona $(p<0,05)$.
Tabla 3. Frecuencia de metilación del área promotora

\begin{tabular}{|lrr|}
\hline & \multicolumn{1}{c}{ Positivo } & \multicolumn{1}{c|}{ Negativo } \\
\hline p16 & $41,4 \%(28)$ & $58,6 \%(42)$ \\
hMLH1 & $11,40 \%(8)$ & $88,60 \%(62)$ \\
APC1A & $52,90 \%(37)$ & $47,1 \%(33)$ \\
CDH1 & $70 \%(49)$ & $29 \%(21)$ \\
FHIT & $42,90 \%(30)$ & $57,10 \%(40)$ \\
\hline
\end{tabular}

Tabla 4. Indice de metilación promedio 0,44

\begin{tabular}{|crr|}
\hline Indice de metilación & \multicolumn{2}{c|}{$\%(\mathrm{n})$} \\
\hline 0 & $11,59 \%$ & $(8)$ \\
0,2 & $17,39 \%$ & $(25)$ \\
0,4 & $30 \%$ & $(21)$ \\
0,6 & $21,4 \%$ & $(15)$ \\
0,8 & $17,1 \%$ & $(12)$ \\
1 & $1,43 \%$ & $(1)$ \\
\hline
\end{tabular}




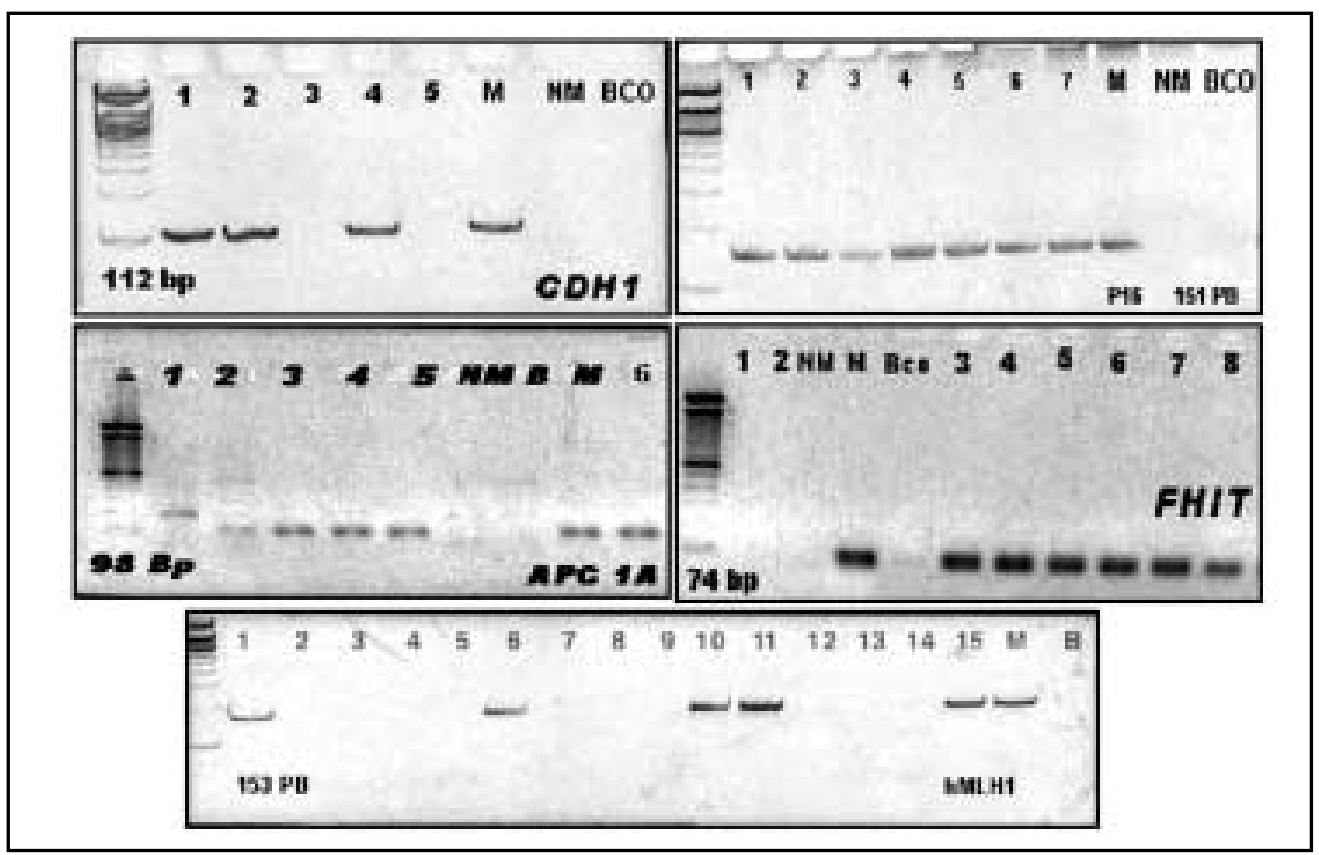

Figura 1. Fotografía compuesta de geles de Agarosa que muestra el resultado del análisis de metilación en los 5 genes estudiados donde se puede observar el tamaño variable de las bandas amplificadas.

$\mathrm{M}=$ control positivo ADN genómico metilado y modificado; $\mathrm{NM}=$ control negativo ADN genómico no metilado y modificado: y B = Blanco.

\section{DisCUSIÓN}

Numerosos estudios previos han demostrado la importancia de la metilación del $\mathrm{ADN}$ en los cánceres en humanos y se han enfocado en áreas del genoma que podrían tener un efecto funcional resultando en inactivación de uno o más genes $^{16,24,37,38}$. La mayoría de los tumores tienen muchos genes metilados, sin embargo los perfiles de metilación son bastantes característicos en cánceres específicos, revelando muchas veces características biológicas y pronósticas de los tumores $35,39,40$. El test de metilación específico mediante PCR detecta hasta $0,1 \%$ de ADN metilado constituyéndose en un método altamente sensible que permite la detección incluso en las primeras etapas del desarrollo carcinogénico ${ }^{20}$.

Estudiamos el patrón de metilación mediante 5 genes, cada uno de ellos relacionados con diferentes procesos carcinogénicos alterados en tumores en humanos.

Observamos frecuente metilación ( $>40 \%)$ en 4 de los 5 genes estudiados, el gen hMLH1 fue el único que mostró una baja frecuencia de metilación $(11,4 \%)$. Nuestros resultados concuerdan con el hecho que, aun cuando se estima que la metilación sea uno de los principales mecanismos que determinen la inactivación de este gen, el cáncer esporádico de mama no ha sido asociado con altos niveles de inestabilidad microsateli$\operatorname{tal}^{41,42}$. Se observó menor frecuencia de metilación en pacientes mapuches $(p=0,03)$. Este hecho es interesante y concuerda con nuestros datos en vesícula biliar, donde ninguno de los pacientes con inestabilidad microsatelital de alto grado es de raza mapuche (Roa JC. Datos no publicados).

En nuestro estudio del gen APC observamos un alto porcentaje de metilación (52,9\%), el cual se relacionó con mayor tamaño tumoral y menor grado de diferenciación tumoral. Siendo estos valores un poco más frecuentes que los encontrados en otra serie en la que se analizó un total de 77 muestras de cáncer de mama que mostró 34\% de positividad para el (MSP) ${ }^{43}$.

Nuestros casos presentaron $41,4 \%$ de metilación para el gen CDKN2A . Existen otras 2 series 
de 100 y 104 tumores primarios de mama que mostraron, mediante el mismo análisis, similares resultados con $31 \%$ y $32 \%$ de metilación respectivamente 44,45 . Nuestros casos mostraron mejor sobrevida $(p=0,04)$. Sin embargo, estos resultados no concuerdan a los usualmente publicados, que muestran una tendencia a peor pronóstico ${ }^{46-48}$ en este grupo de pacientes, las razones para este hallazgo son desconocidas, aunque debemos considerar que nuestro grupo de estudio está compuesto por $70 \%$ de casos en etapas I y II.

Nuestro análisis mostró porcentajes de 42,9\% de metilación para el gen FHIT en muestras de tumores primarios de mama, los cuales fueron concordantes con otros estudios que obtuvieron entre $31 \%$ y $48 \%$, respectivamente para tumores de mama. Y de 86\% para líneas celulares de cáncer de mama ${ }^{33,49}$. Los casos que presentaban metilación mostraron una tendencia a estar presentes en tumores sin expresión inmunohistoquímica de receptores de estrógeno y progesterona.

Encontramos una alta frecuencia de metilación para $\mathrm{CDH} 1$ gen, alcanzando $70 \%$ de los casos. Con una tendencia significativa a estar más frecuentemente metilado en casos con menor diferenciación tumoral. Estas cifras son concordantes con otras series que mostraron frecuencia de metilación de entre $41 \% 50$ a $79 \% 30,51$, tanto en tumores de tipo lobulillar como ductal.

Además, analizamos el índice de metilación, que corresponde a una relación entre el total de genes metilados y el total de genes analizados. El promedio del índice de metilación en todos los

\section{REFERENCIAS}

1. Medina E, KaEmPfFer AM. Mortalidad por cáncer en Chile. Consideraciones epidemiológicas. Rev Méd Chile 2001; 129: 1195-202.

2. Landis SH, Murray T, Bolden S, Wingo PA. Cancer statistics, 1998. CA Cancer J Clin 1998; 48: 6-29.

3. Maggard MA, Thompson JE, Ko CY. Why do breast cancer mortality rates vary across states? Am Surg 2003; 69: 59-62.

4. Quinn MJ. Cancer trends in the United States, a view from Europe. J Natl Cancer Inst 2003; 95: 1258-61.

5. JHANWAR-UniYal M. BRCA1 in cancer, cell cycle and genomic stability. Front Biosci 2003; 8: s1107-17. casos estudiados fue de 0,44 (Tabla 4). Así, cuando el índice de metilación fue mayor, es decir cercano a 1, se correlacionó con menor grado de diferenciación tumoral fue menor. Nuestros resultados muestran que múltiples genes están metilados durante el proceso de carcinogénesis mamaria y encontramos metilación muy frecuente $(>40 \%)$ para los genes CDKN2A, FHIT, APC y CDH1. La metilación de estos genes se correlacionó en algunos casos con parámetros de mal pronóstico, sin embargo no mostró resultados concluyentes respecto de su valor pronóstico en la sobrevida de los pacientes.

Particular importancia presenta la metilación como mecanismo carcinogenético porque permite explorar la importancia del medio ambiente y factores asociados como dieta y exposición a carcinógenos. Este evento epigenético tiene la particularidad que puede ser heredado a la progenie ${ }^{10}$. Este hecho se ve apoyado en el estudio de poblaciones migratorias que mantienen el riesgo de desarrollar cánceres específicos que las poblaciones donde geográficamente se establecen durante 1 e incluso 2 generaciones ${ }^{52,53}$. Desde el punto de vista genético molecular, permite entender cómo se afectan simultáneamente diferentes mecanismos de control y crecimiento celular, de invasión y metástasis ${ }^{16,24,37}$.

Concluimos que el estudio del perfil de metilación en el cáncer de mama puede representar una herramienta útil en el entendimiento de la biología y conducta de estos tumores, y que estudios con mayor número de pacientes ayudarán a establecer su real utilidad y aplicación en oncología.

6. WelCSH PL, KINg MC. BRCA1 and BRCA2 and the genetics of breast and ovarian cancer. Hum Mol Genet 2001; 10: 705-13.

7. Shannon C, SMith IE. Breast cancer in adolescents and young women. Eur J Cancer 2003; 39: 2632-42.

8. Adem C, Soderberg CL, Cunningham JM, Reynolds C, Sebo TJ, Thibodeau SN et al. Microsatellite instability in hereditary and sporadic breast cancers. Int J Cancer 2003; 107: 580-2.

9. Buchrolz TA, Weil MM, Story MD, Strom EA, Brock WA, McNeEsE MD. Tumor suppressor genes and breast cancer. Radiat Oncol Investig 1999; 7: 55-65.

10. Estelier M, Fraga MF, Guo M, Garcia-Foncilas J, Hedenfalk I, Godwin AK et al. DNA methylation patterns in hereditary human cancers mimic 
sporadic tumorigenesis. Hum Mol Genet 2001; 10: 3001-7.

11. Baylin SB, Herman JG. DNA hypermethylation in tumorigenesis: epigenetics joins genetics. Trends Genet 2000; 16: 168-74.

12. Jones PA, LAIRD PW. Cancer epigenetics comes of age. Nat Genet 1999; 21: 163-7.

13. WOLFFE AP, MATZKE MA. Epigenetics: regulation through repression. Science 1999; 286: 481-6.

14. Gото T, Monk M. Regulation of X-chromosome inactivation in development in mice and humans. Microbiol Mol Biol Rev 1998; 62: 362-78.

15. TAKAI D, JoneS PA. Comprehensive analysis of CpG islands in human chromosomes 21 and 22. Proc Natl Acad Sci USA 2002; 99: 3740-5. Epub 2002 Mar 12.

16. ROBERTSON KD, Jones PA. DNA methylation: past, present and future directions. Carcinogenesis 2000; 21: 461-7.

17. Merlo A, Herman JG, Mao L, Lee DJ, Gabrielson E, BuRger PC ET AL. 5' CpG island methylation is associated with transcriptional silencing of the tumour suppressor p16/CDKN2/MTS1 in human cancers. Nat Med 1995; 1: 686-92.

18. Issa JP, Ottaviano YL, Celano P, Hamliton SR, DavidSON NE, BAYLN SB. Methylation of the oestrogen receptor $\mathrm{CpG}$ island links ageing and neoplasia in human colon. Nat Genet 1994; 7: 536-40.

19. RAZIN A, CEDAR H. DNA methylation and gene expression. Microbiol Rev 1991; 55: 451-8.

20. Herman JG, Graff JR, Myohanen S, Nelkin BD, BAYLIN SB. Methylation specific PCR: a novel PCR assay for methylation status of $\mathrm{CpG}$ islands. Proc Natl Acad Sci USA 1996; 93: 9821-6.

21. FEARON E. Tumor supressor genes. In: Vogelstein Bert KK, editor. The genetic basis of cancer. Second Edition ed. New York: Mc Graw Hill; 2002; 197-206.

22. Christoph. CDL. Tumor Genome Instability. In: Kenneth. VBK, editor. The genetic basis of cancer. New York: Mc Graw Hill; 2002; 129-30.

23. BerX G, Van Roy F. The E-cadherin/catenin complex: an important gatekeeper in breast cancer tumorigenesis and malignant progression. Breast Cancer Res 2001; 3: 289-93. Epub 2001 Jun 28.

24. WAJED SA, LAiRd PW, DeMEeSTER TR. DNA methylation: an alternative pathway to cancer. Ann Surg 2001; 234: 10-20.

25. Aaltonen LA, Peltomaki P, Leach FS, Sistonen P, Pylkkanen L, Mecklin JP et al. Clues to the pathogenesis of familial colorectal cancer. Science 1993; 260: 812-6.

26. Fearnhead NS, Britton MP, Bodmer WF. The ABC of APC. Hum Mol Genet 2001; 10: 721-33.

27. Soravia C, Bapat B, Cohen Z. Familial adenomatous polyposis (FAP) and hereditary nonpolyposis colorectal cancer (HNPCC): a review of clinical, genetic and therapeutic aspects. Schweiz Med Wochenschr 1997; 127: 682-90.

28. JubB AM, Bell SM, QuiRke P. Methylation and colorectal cancer. J Pathol 2001; 195: 111-34.

29. LiggetT WH JR, SidRanSKY D. Role of the p16 tumor suppressor gene in cancer. J Clin Oncol 1998; 16: 1197-206.

30. ZemLakova VV, Zhevlova AI, Strel'Nikov VV, LubCHENKo LN, VishnevsKaia IA V, TRET'iakova VA et al. Abnormal methylation of several tumor suppressor genes in sporadic breast cancer. Mol Biol (Mosk) 2003; 37: 696-703.

31. Bian YS, O sterheld MC, Fontoluet C, Bosman FT, BenHATTAR J. p16 inactivation by methylation of the CDKN2A promoter occurs early during neoplastic progression in Barrett's esophagus. Gastroenterology 2002; 122: 1113-21.

32. Huiping C, Kristjansdottir S, Bergthorsson JT, Jonasson JG, Magnusson J, EgiLSSON V ET aL. High frequency of LOH, MSI and abnormal expression of FHIT in gastric cancer. Eur J Cancer 2002; 38: 728-35.

33. Zochbauer-Muler S, Fong KM, Maitra A, Lam S, Geradts J, AshfaQ R et al. 5' CpG island methylation of the FHIT gene is correlated with loss of gene expression in lung and breast cancer. Cancer Res 2001; 61: 3581-5.

34. Berd G, Becker KF, Hofler H, van Roy F. Mutations of the human E-cadherin (CDH1) gene. Hum Mutat 1998; 12: 226-37.

35. Maruyama R, Toyooka S, Toyooka KO, Virmani AK, Zochbauer-Muler S, Farinas AJ et al. Aberrant promoter methylation profile of prostate cancers and its relationship to clinicopathological features. Clin Cancer Res 2002; 8: 514-9.

36. Maruyama R, Toyooka S, Toyooka KO, Harada K, VIRMANI AK, Zochbauer-Mu山er S, et al. Aberrant promoter methylation profile of bladder cancer and its relationship to clinicopathological features. Cancer Res 2001; 61: 8659-63.

37. YANG X, YAN L, DavidSON NE. DNA methylation in breast cancer. Endocr Relat Cancer 2001; 8: 11527. 
38. RAZIN A, CEDAR H. DNA methylation and genomic imprinting. Cell 1994; 77: 473-6.

39. Kang GH, Lee S, KIm JS, Jung HY. Profile of aberrant $\mathrm{CpG}$ island methylation along the multistep pathway of gastric carcinogenesis. Lab Invest 2003; 83: 635-41.

40. Esteler M, Corn PG, Baylin SB, Herman JG. A gene hypermethylation profile of human cancer. Cancer Res 2001; 61: 3225-9.

41. Caldes T, Pérez-Segura P, Tosar A, De la Hoya M, Díaz-RuBio E. Low frequency of microsatellite instability in sporadic breast cancer. Int J Oncol 2000; 16: 1235-42.

42. Siah SP, Quinn DM, Bennett GD, Casey G, Flower RL, Suthers G ET AL. Microsatellite instability markers in breast cancer: a review and study showing MSI was not detected at 'BAT 25' and 'BAT 26' microsatellite markers in early-onset breast cancer. Breast Cancer Res Treat 2000; 60: 135-42.

43. Virmani AK, Rathi A, Sathyanarayana UG, Padar A, Huang CX, Cunnigham HT et al. Aberrant methylation of the adenomatous polyposis coli (APC) gene promoter $1 \mathrm{~A}$ in breast and lung carcinomas. Clin Cancer Res 2001; 7: 1998-2004.

44. Silva J, Silva JM, Domínguez G, García JM, Cantos B, Rodríguez R ET AL. Concomitant expression of p16INK4a and p14ARF in primary breast cancer and analysis of inactivation mechanisms. J Pathol 2003; 199: 289-97.

45. Nielsen NH, Roos G, Emdin SO, LANdBeRg G. Methylation of the p16(Ink4a) tumor suppressor gene 5'-CpG island in breast cancer. Cancer Lett 2001; 163: 59-69.
46. Vo QN, Geradts J, Boudreau DA, Bravo JC, SCHNEIDER BG. CDKN2A promoter methylation in gastric adenocarcinomas: clinical variables. Hum Pathol 2002; 33: 1200-4.

47. Maeda K, Kawakami $\mathrm{K}$, Ishida $\mathrm{Y}$, Ishiguro $\mathrm{K}$, Omura $\mathrm{K}$, Watanabe $\mathrm{G}$. Hypermethylation of the CDKN2A gene in colorectal cancer is associated with shorter survival. Oncol Rep 2003; 10: 935-8.

48. Lung JT, Chang KJ, Chen JC, Lee CC, Cheng YM, Hsu HC ET AL. Hypermethylation of the p16 gene in sporadic T3NOM0 stage colorectal cancers: association with DNA replication error and shorter survival. Oncology 1999; 57: 149-56.

49. Yang Q, Nakamura M, Nakamura $Y$, Yoshimura G, Suzuma T, UmemuRa T ET AL. Two-hit inactivation of FHIT by loss of heterozygosity and hypermethylation in breast cancer. Clin Cancer Res 2002; 8: 2890-3.

50. Sarrio D, Moreno-Bueno G, Hardisson D, SánchezEstevez C, Guo M, Herman JG et al. Epigenetic and genetic alterations of APC and CDH1 genes in lobular breast cancer: relationships with abnormal E-cadherin and catenin expression and microsatellite instability. Int J Cancer 2003; 106: 208-15.

51. Droufakou S, Deshmane V, Roylance R, Hanby A, TOMLINSON I, HART IR. Multiple ways of silencing Ecadherin gene expression in lobular carcinoma of the breast. Int J Cancer 2001; 92: 404-8.

52. Mack TM, Walker A, Mack W, Bernstein L. Cancer in Hispanics in Los Angeles County. Natl Cancer Inst Monogr 1985; 69: 99-104.

53. MCCREDIE M. Cancer epidemiology in migrant populations. Recent Results Cancer Res 1998; 154: 298-305. 